\title{
О значении лингвистического поворота в исследовании права
}

\author{
P. В. Насыров \\ Алтайский государственный университет \\ 656000, Барнаул, пр. Социалистический, 68, E-mail: nasirov.rafail@yandex.ru
}

\begin{abstract}
В статье ставится цель обосновать значимость для познания юридических явлений лингвистического поворота, который стал ярко проявляться в социогуманитарных исследованиях с начала прошлого века. Лингвистический поворот рассматривается как следствие развернувшегося с конца XIX века интеллектуального движения под названием «критика метафизики", которое оказало влияние на большинство философских течений XX века - феноменологию, герменевтику, экзистенциализм, аналитическую философию, прагматизм и иные. Лингвистический поворот возник в процессе критики метафизики как оторванности философских и научных теорий от реальной жизни. В это движение исследовательской мысли активно включились и юристы, так как оно предполагает погружение в непосредственный процесс социальной коммуникации, значительная часть которого соответствует понятию предмета правового регулирования. В статье обосновывается отличие наук фундаментальных и прикладных, в которых предмет познания и понимание истины не являются тождественными. Лингвистический поворот рассматривается как один из способов обеспечения связи правотворчества и юридических исследований с реально существующим предметом правового регулирования и юридической практикой. Признается, что в российском доктринальном правосознании проявляется дефицит погружения в объективно существующую социальную реальность, важнейшим аспектом которой выступает язык. Приводятся примеры того, что язык - это не просто знаковая система, выступающая средством выражения мысли о действительности, но средство раскрытия самой этой действительности человеку теми сторонами и аспектами, которые заданы используемыми для её описания словами. Делается вывод о необходимости учитывать в правовых теориях и законодательных конструкциях особенности российского правосознания, которые отражены в семантике русского языка.

Ключевые слова: лингвистический поворот; право; юридическая наука; язык; правосознание
\end{abstract}

\section{On the importance of linguistic turn in law studies}

\author{
R. V. Nasyrov \\ Altai State University \\ 656000, Barnaul, pr. Socialisticheskii,68. E-mail: nasirov.rafail@yandex.ru.
}

\begin{abstract}
The article aims to substantiate the significance of the study of the linguistic turn for the knowledge of legal phenomena, which has been vividly manifested in socio-humanitarian studies since the beginning of the last century. The linguistic turn is viewed as a consequence of the intellectual movement unfolding since the end of the 19th century called "criticism of metaphysics", which influenced most of the philosophical schools of the 20th century - phenomenology, hermeneutics, existentialism, analytical philosophy, pragmatism and others. The linguistic turnaround arose in the process of criticism of metaphysics as the isolation of philosophical and scientific theories from real life. Lawyers were actively involved in this movement of research thought, si nce it involves immersion in the direct process of social communication, much of which corresponds to the concept of the subject of legal regulation. The articlesubstantiates the difference between fundamental and applied sciences, in which the object of knowledge and, accordingly, the understanding of truth are not identical. The linguistic turn is considered as one of the ways to ensur e the connection of law-making and legal research with a really existing subject of legal regulation and legal practice. It is recognized that in the Russian doctrinal sense of justice there is a lack of immersion in an objectively existing social reality, the most important aspect of which is language. There are examples given here to prove the fact that language is not jus t a sign system, acting as a means of expressing thoughts about reality, but this reality itself is revealed to a person by those parties and aspects spec ified by the words used to describe it. The conclusion is made about the need for legal theories and l egislative structures to take into account the peculiarities of the Russian legal consciousness, which are reflected in the semantics of the Russian language.
\end{abstract}

Key words: Iinguistic turn; law; I egal science; Ianguage; legal consciousness 
В статье ставится цель обосновать значимость для познания юридических явлений лингвистического поворота, который ярко проявился в социогуманитарных исследованиях с начала прошлого века. Внедрение в философский и научный дискурс концепта «лингвистический поворот» связывается с именем американского философа Р. Рорти, под редакцией которого в 1967 году была опубликована одноименная коллективная монография, посвященная проблемам философии языка [Rorty 1967]. Но исследователи обраща ют внимание на скорее риторический характер этого словосочетания и указывают на то, что «что фактически поворот к языку произошел за полвека до возникновения соответствующего обозначения» [Инишев 2012: 186].

Лингвистический поворот необходимо рассматривать как проявление и следствие развернувшегося с конца XIX века интеллектуального движения под названием «критика метафизики» и возникновения такого направления мысли как «философия жизни», которое, как известно, оказало влияние на большинство философских течений XX века - феноменологию, герменевтику, экзистенциа лизм, а на литическую философию, пра гматизм и иные. Лингвистический поворот возник в процессе критики метафизики как оторванности философских и научных теорий от реальной жизни. Соответственно, в это движение исследовательской мысли активно включились и юристы, так как оно предполагает погружение в непосредственный процесс социальной коммуникации, значительная ча сть которого соответствует понятию предмета правового регулирования. Именно в русле интеллектуального движения под название м «критика метафизики» возникли такие теории права как социологическое направление в юриспруденции, феноменологическая, психологическая, реалистическая школа права и иные; с философией жизни коннотирует название и содержание концепцииЕ. Эрлиха теория «живого права».

Суть лингвистического поворота в современных науках об обществе и человеке предварительно можно кратко выразить, преобразовав известное высказывание основателя методологии классической науки Р. Декарта - «Я мыслю, следовательно, я существую» - в «Я говорю, следовательно, я существую». Для обоснования допустимости такого утверждения сошлемся на М. Хайдеггера, который утверждал: «Для речи нужны говорящие; но не только так, как для следствия нужна причина. Говорящие скорее сами присутствуют лишь в своем говорении» [Хайдеггер 1993: 264]. В науках практических (каковой является и юриспруденция) главным является вопрос не «Что?», а «Как?». Если учесть замеченное самим Р. Декартом различие фундаментальных и прикладных исследований, то картезианский принцип познания приобретает вид: «Я существую (практикую, говорю) так, как я мыслю». В соответствии с этой дедуктивной установкой в юридической науке и практике возникает отраженное в учебниках теории права представление о том, что первой стадией правового регулирования выступает законотворчество, то есть формирование правовой реальности начина ется с мысли законодателя. Но такое, условно говоря, дедуктивное восприятие процесса правового регулирования в российской действительности приобрело негативные формы правового идеализма, законотворческого волюнтаризма, «голого» законодательства ит.п.

Стоит признать, что и отечественна я юриспруденция до сих пор несет печать свое го искусственного происхождения. Правовая наука в России возникла одномоментно в результате заимствования системы преподавания права в западноевропейских университетах. Первыми учеными-юристами были иностранцы, преподававшие «право на туры» (естественное право) и римское право. Юридическую науку в России до сих пор воспринима ют не как явление, постепенно и естественно вырастающее из потребностей са мой общественной жизни, а как результат за имствования. Несмотря на плеядувыда ющихся имен в российской философии и теории права, исследователи отмечают: «Юридическая наука в России имеет весьма слабые прикладные школы и методологии, часто без соответствуюей орга низа ционной инфра структуры. В целом на блюдается зна чительный отрыв массового, обыденного правосознания от правосознания официа льно-а кадемического» [Синюков 2010: 36]. Это предопределило устойчивое представле ние о существовании некое го идеальноуниверсального права, которое лишь необходимо внедрить в общественную жизнь. Доктринальное правосознание стало характеризоваться преобладанием дедуктивно-логического мышления при явном дефиците индуктивно-практического подхода к изучению правовыхявлений.

Очевидно, что юристам ближе индуктивный метод познания, значимость которого доказал другой (нарядус Р. Декартом) основатель рационализма Нового времени - Ф. Бекон. В афоризме «Знание - сила» английский философ имеет в виду знание, почерпнутое из опыта: «Если са ми понятия, соста вляя основу всего, спута ны и не обдума нно отвлечены от вещей, то нет ниче го про чного В том, что построено на них. Поэтому единственна я надежда - в истинной индукции» [Бекон 1978: 13-14]. С этой индуктивной точки зрения, формула лингвистического поворота в социогуманитарных исследованиях приобретает иной вид - «Я мыслю так, как я существую, практикую и, наконец, говорю». Казалось бы, речь идет об особенностях англо-саксонского стиля мышления с его эмпиризмом и пра гма тизмом. Но стоит признать, что для прикладных наук такой пра ктически ориентированный ха рактер исследования релевантен их предмету и методологии. Так, О. Холмс (младший) сформулировал принцип, подтвержденный историей и самим механизмом функционирования права: «Жизнь права не была логичной, она была опытом» [цит. по: Адыгезалова 2012:83]. Представители контине нтальной (романо-германской) правовой традиции не могут отрицатьтого, что римские юристы фо рмулировали свои общие положения о праве в контексте юридической пра ктики. В определении права Цельса «Jus est ars boni et aequi»слово «ars» точнее переводить как «искусство, мастерство», то есть право - это не просто наука, знание о добре испра ведливости, а именно практика их воплощения в конкретныха ктах реализацииправа.

Обосновыва я дедуктивный принцип познания, Р. Декарт отметил, что его тезисуо том, что до обнаружения очевидной истины всё сомнительное необходимо считать ложным, нельзя следовать в сфере «жизненной практики»: «Ибо, что касается жизненной пра ктики, то, поскольку зачастую мы должны действовать прежде, чем изба виться от сомнений, мы нередко бываем вынуждены усвоить то, что является всего лишь правдоподобным, а иногда просто выбрать одно из двух, если ни одно из них не представляется более правдоподобным, чем другое» [Декарт 1989:315]. Речь идет о не вполне еще отрефлексированном и учтенном в российском доктринальном правосознании отличии наук фундаментальных и прикладных, в которых предметпознания и понимание истины не являются тождественными. Лингвистический поворот допустимо рассматривать как один из способов обеспечения связи правотворчества и юридических исследований с реально существующим предметом правового регулирования и юридической практикой. Разумеется, научное познание, в том числе и юридическое, предполагает дедукцию, выведение нового знания из общих положений - аксиом, идей, принципов. Но стоит признать, что в отечественном доктринальном правосозна нии проявляется дефицит погружения в объе ктивно суще ствующую социа льную реальность, ва жнейшим аспектом которой выступает в том числе иязык.

Лингвистический поворот в социогуманитарных исследованиях основан на осознании того, что язык является не только средством социа льной коммуника ции, но и фа ктором, определяющим её содержательные аспекты. М. Хайдеггер пишет: «Язык есть дом бытия. В жилище языка обита етчеловек. Мыслители и поэты - хра ните лиэтого жилища. Ихстра жа - осуществление открытости бытия, насколько они дают ей слово в своей речи, тем сохраняя её в языке. Мысль не потому становится прежде всего действием, что от нее исходит воздействие или что она прила га ется к жизни. Мысль де йствует, посколькумыслит» [Хайдеггер 1993: 192]. Философ разлимает язык и речь, то есть не всякое высказывание и суждение соответствуетязыку как «дому бытия». В приведенной цитате М. Хайдеггер 
связыва ет надежду и обяза нность рефлексивно выражать в речи функцию языка ка к «дома бытия» с мыслителями, которые способны, прежде чем сформулировать общие положения о предмете познания, погрузиться в него: «Всякое воздействие покоится в бытии, но на пра влено на сущее. Мысль, на против, допуска ет бытию захватить себя, чтобы сказать истину бытия» [Хайде ггер 1993: 192]. Допустимо утверждать, что российское доктринальное правосознание не достигло еще состояния самоидентификации и не выразило истину отечественного правового бытия, так как не погрузилось в него.

Российские правоведы, разрабатывая законопроекты и стремясь избежать «голого» за конотворчества, должны внимательно вслушиваться в речь носителей обыденного правосознания, та к как в ней спонтанно и поэтому искренне (непредвзято) проявляются не поверхностные, а глубинные уста новки сознания. Так, до сих пор фактические брачные отношения в русской речи (вопреки законам юридиче ским и логическим) называ ют «гражданским бра ком», что не есть проявление юридической безграмотности, а свидетельствует о сохра нении традиционного представления о том, что брак является не только светским юридическим договором, но ичем-то бо́льшим. Этим можно объяснить и относительно низкий процент брачных договоров в РФ - менее 10\% (в США И ЕС - около 70\%) [Левушкин 2016: 5]. Оценка такой статистики лишь как проявление пошлости и отсталости российского правосознания носит поверхностный характер иявляется примером игнорирования особенностей отечественного правосознания.

Язык - это не просто зна ковая система, выступа ющая средством выражения мысли о действительности, но средство раскрытия самой этой действите льности человеку теми сторонами и аспе ктами, которые заданы используемыми для её описа ния слова ми. Слова как носители понятий (обобщений) важны и необходимы, но в конкретном дискурсе значение слова может быть задано акцентом на одной из многочисленных коннота ций этого слова. Поэтому лишь отчасти верно определение коннотациичерез указание на то, что она выра жает несущественные устойчивые призна ки выра жаемого еюпонятия [Апресян 1995: 159]. Известный философ и семиотик Р. Барт понятию коннотации придает идеологическое значение, так как коннотативное означаемое «обладает всеобъемлющим, глобальным, расплывча тым ха рактером: это - фрагмент идеологии» [Барт 1975: 159]. Поэтому в процессе восприятия и оценки а кта публичной речи необходимо "держать паузу", то есть не торопиться с выводом о его смысле, учитывать контекст и цель речевого акта. Коннотативная лингвистика позволяет понять, что в обществе «на базе первичной системы, образуемой естественным языком, постоянно возникают системы вторичных смыслов" [Барт 1975: 158]. Р. Барт, учитывая тот факт, что в современной политической жизни огромное место за нима ет процесс ма нипуляции созна нием людей, пишет: «У нас пока нет социологии слова. Нам лишь известно, что слово есть форма власти и что особая группа людей (нечто среднее ме жду корпорацией и классом) определяется как раз тем, что более или менее безраздельно владеет языком на ции» [Барт 2008: 117].

Приходится признать, что российское общественное сознание является довольно удобным объектом манипуляции. В правосознании выделяются рациональные и эмоциональные компоненты. Вполне допустимо на зывать такую особенность российского правосознания как преобладание в нем образно-эмоциональной составляющей. Это соответствует выводам лингвистов, которые в своих сравнительных исследованиях фиксируют важную роль в русском языке эмоционально-оценочныхслов и выражений. Соответственно, в правовом воспитании и юридическом образовании органично в сознание человека войдут те знания, которые пропущены через этнические оценочные чувства и образы. Уче ные, изуча ющие российскую языковую картину мира, приходят к выводу: «Национальнокультурные стереотипы включают не столько рациональные основания оценки, сколько эмоциональные, субъектные характеристики обозначаемого [Коновалова 2012: 260]. Этот факт отражается в самих традиционных юридических терминах, многие из которых не просто называли правовые явление, а образно представляли и оценивали их; например, в средневековой Руси правонарушение «обида » или «лихое дело», судебный спор - «розлюбье»ит.д.

В 90-х годах прошлого века сменились идеологические ориентиры развития общества, что предопределило значительное увеличение объема иностранной терминологии в текстах российских законов. По мнению Туранина В.Ю., чрезмерное использование за имствова нной ле ксики не всегда носит конструктивный ха рактер и вызва но неоправданным жела нием разработчиковза конопроектов подчеркнуть их на укообразность, придать им дополните льную «солидность». Этотже автор обращаетвнима ние на фа кты неадекватной трактовки значения иностранных слов и предлагает провести отсев терминов, не вписывающихся в российский юридический язык [Тура нин 2009: 14]. Это предложение, казалось бы, имеетотношение лишь к прикладной сфе ре правовой деятельности, то есть к такому элементуюридической техники как язык правовыха ктов. Но установка на внимательное ипринципиа льное отношение к юридической терминологии важна идля теоретиков права при решении вопросов о сущностиправа, его ценностии функциях.

Так, этимология слова «закон» соответствует такой особенности отечественного правосознания как признание приоритета не регулятивной, а охранительной функции формального права. Приставка «за придает всему слову значение того, что находится за пределами или не соответствует тому, что выражено в корне этого слова. Оказывается, что «кон» - это «нача ло», то, что было «искони». Если вспомнить приведенный выше пример с брачным договором, то традиционное представление о том, что браки «заключаются на небесах» соответствует понятию «кона », а нотариально заверенный брачный к онтракт заключается за пределами «кона », то есть по «закону». Наиболее точно глубинная этимология слова «закон» раскрыта в словаре А.В. Семенова как “установление власти, противоположное традициям» [Семенов 2003]. Заметно, что в обыденном российском правосознании сохраняется такое восприятие формального права, что отражается в известной постановке вопроса - «По за кону или по совести?».

За ве ршим ста тью конкретным примером, демонстрирующим значение лингвистического а нализа формулировокофициа льных текстов. Тот фа кт, что иностранные слова по сравнению с русскими звучат нейтра льно и менее эмоционально на гружены, оправдывает их использование в качестве эвфемизмов; целесообразно вместо слов “калека» и "старик» употреблять термины «инвалид» и «пенсионер». Но существуют негативные, чрезвычайные, исключительные ит.д. социальные явления, которые в созна нии должны так и восприниматься, а в речи называться словами с соответствующими не только значениями, но и коннотациями. Право по своей природе нормативно и поэтому то, что законом регулируется, может начать оцениваться как нечто «нормальное». Так, естественными «уполномоченными» по пра вам ребенка должны быть его родители, дедушка и ба бушка и иные родственники. Важно в общественном сознании сохранять представление о чрезвычайном характере случаев, когда в качестве такого уполномоченного по правам ребенка выступа ют официальные органы и лица. Но институты прав ребенка, ювенальной юстиции и информация о них внедряются в России таким образом, что невольно возникает презумпция, что от окружающих и даже близких родственников постоянно исходит угроза правам и интересам ребенка, а основным его защитником призвано быть государство. Исчезает представление о том, что речь идет о детях-сиротах, неблагополучных семьях и специализированной судебно-правовой системе защиты прав несовершеннолетник. Иностранный эпитет «ювенальный» звучит нейтрально и в духе НЛП (нейролинвистического программирования) неосознанно настра ивает на восприятия этого вида юстиции какявления «нормального», а не чрезвычайного.

Одним из требований пра вотворческой техники выступа ет соответствие на именования (за головка) нормативного правового акта его назначению и предмету регулирования. Специалисты в сфере за конодательной техники пишут: «За головок за кона - один ив важнейших формальных реквизитов, играющих первостепенную роль в оценочном восприятии, понимании за конодательного текста» 
[Законодательная техника 2000: 117]. Конвенция о правах ребенка (одобрена Генеральной Ассамблеей ООН 20 ноября 1989 года) признает, что «ребенкудля полного и гармоничного развития его личности необходимо расти в семейном окружении, в атмосфере счастья, любви и понимания». В этой Конвенции закреплено, что для обеспечения этого фундаментального права необходима находяща яся вне прямого воздействия закона и официальной власти естественная ячейка общества, то есть семья, которой «должны быть предоставлены необходимые защита и содействие, с тем, чтобы она могла полностью возложить на себя обязанности в рамках общества ». Оче видно, что не обходимость в непосредственном уча стии государства возника етв той чрезвычайной ситуа ции, когда для защиты прав ребенка оказываются недостаточными возможности естественной ячейки общества, то есть семьи, или семья небла гополучна я, или ребенок оказался сиротой. В Федеральном за коне от 27.12.2018 N 501-ФЗ "Об уполномоченных по правам ребенка в Российской Федерации" в части 1 ст. 2 закрепляется: "Деятельность Уполномоченного направлена на обеспечение гарантий государственной защиты прав и законных интересов детей, реализации и соблюдения прав и законных интересов детей государственными органами, органами местного самоуправления и должностными лицами». В предмет правового регулирования, связа нный с за щитой пра в и интересов человека, входят чрезвычайные и конфликтно опа сные общественные отношения. В противном случае в обязанности Уполномоченного по правам ребенка пришлось бы включить мониторинг и контроль в целом всей политики государства в сферах социально-экономической, образования, культуры, СМИ, интернета и т.д. В этих сферах общественной жизни и создаются условия для сохранения и благополучия (или разрушения) семьи как той ячейки общества, где и может быть реально обеспечено провозглашенное в Конвенции 1989 года основное право ребенка «расти в семейном окружении, в атмосфере счастья, любви и понимания».

С точки зрения юридической лингвистики, не стоит иностранный эпитет «ювенальный» переводить на русский язык и в перечень конституционной, уголовной, административной и т.д. юстиций вставлять термин «детская юстиция». Но целесообразно использовать словосочетание «по делам», которое вызывает в русском языке коннотации с чем-то дискретным, непривычным, чрезвычайным. Вполне адекватно функции соответствующих официа льных лиц и органов отражались бы в терминах «Уполномоченный по делам ребенка» и «ютиция по делам несовершеннолетних».

Подводя итог, укажем, что лингвистический поворот в исследовании права может стать одним из фа кторов, способствующих достижению отечественным доктринальным пра восознанием состояния са моидентифика ции. В России существует довольно развитая и воплощенна я в многочисленных теоретических текстах юридическая наука, но допустимо ста вить вопрос: «Существует ли р оссийска я юридическа я на ука?». Истоки всех отечественных наук связа ны с процессом восприятия в XVIII ве ке иноземных достиже ний, созда нием российской Академии наук и университетов. Признаем, что спустя три века так и не возникла собственно российская юриспруденция, релевантная истории страны, условиям её существования и менталитету. Но почему при этом смогла сформироваться, например, получившая мировое признание отечественная школа языкознания? Ответ содержится в следующем положении академика B.В.Виноградова, которое описывает одно из направлений исследования русского языка XVII-XIX веков: «Изучение семантической истории «за имствованных» слов, связанных с сравнительно-историческим исследованием судьбы их в других языках, в том числе и в родном для них языке, содействует открытию семантических своеобразий русского литературно-языкового процесса» [Виноградов 1999: 4]. Точно так же и юристам необходимо при разработке пра вовых теорий и юридических конструкций погрузиться в реальное российское бытие, в том числе ив семантикуродного русского языка.

\section{Литература}

1. Адыгезалова Г.Э. Социологическая юриспруденция США в XX веке: формирование доктрины, развитие и совершенствование правопорядка. СПб., 2012.

2. Апресян Ю.Д. Избранные труды. Том ІІ. Интегральное описа ние и системная лексикография. М., 1995.

3. Барт Р. Основы семиологии / Структурализм: «за » и «против». М., 1975. - С. 114-163.

4. Барт Р. Нулевая степень письма. М., 2008.

5. Бекон Ф. Сочинения в 2-х томах. Т.2. М., 1978.

6. Виноградов В.В. История слов. М.: РАН. Отделение лите ратуры иязыка. 1999.

7. Декарт Р. Сочинения в 2 тт. Т.1. М., 1989.

8. Законодательная техника: Научно-практическое пособие. М., Городец, 2000.

9. Инишев И. «Иконический поворот» в теориях культуры и общества / Логос, 2012, № 1 (85). - С. 184-211.

10. Конова лова Н.И. Эмоциональная и рациональная оценка в народной фитонимии / Рациональное и эмоциональное в русском языке: Межвузовский сб-к научных трудов. М., 2012. С. 259-266.

11. Левушкин И.Н. Брачныйдоговор в Российской Феде рации. М., 2016.

12. Семнов Ю.В. Этимологический словарь русского языка. М, 2003.

13. Синюков В.Н., Синюкова Т.В. О развитии университетского иприкладного юридического образования в России // Госуда рство и право, 2010, № 3. С. 33-42.

14. Туранин В.Ю. Использование заимствованной терминологии в текстах современных российских законов: возможности и пределы / Современное право, 2009, № 4. - С. 14-17.

15. Хайдеггер М. Путь к языку/ Хайдеггер М. Время и бытие: Статьии выступления. М., 1993. - С. 259-272.

16. Хайдеггер М. Письмо о гума низме / Хайдеггер М. Время и бытие: Статьи ивыступления. М., 1993. -С. $192-220$.

17. Rorty R. (Ed.). The Linguistic Turn. Chicago: University of Chicago Press, 1967.

\section{References}

1. Adygeza lova, G.E. (2012). Sociological jurisprudence of the United States in the XX century: the formation of the doctrine, development and improvement of the rule of law. St. Petersburg (in Russian).

2. Apresyan, Yu. D. (1995). Selected Works. Volume II. Integral description and systemic lexicography. Moscow (in Russian).

3. Bart, R. (1975). Basics of semiology/ Structuralism: "pros" and "cons". Moscow (in Russian).

4. Bart, R. (2008). Zero degree letters. Moscow (in Russian).

5. Ba con, F. (1978). Works in 2 volumes. Vol. 2. Mos cow (in Russian).

6. Vinogradov, V.V. (1999). History of words. Moscow. Russian Academy of Science. De partment of literature a nd language (in Russian). 
7. Descartes, R. (1989). Works in 2 vols. Vol. 1. Moscow (in Russian).

8. Legislative technique. Scientific and practical guide. (2000). Moscow. Gorodets (in Russian).

9. Inishev, I. (2012). "The Iconic Turn" in the Theories of Cul ture and Society. Logos, 1(85), 184-211 (in Russian).

10. Konova lova, N.I. (2012). Emotional and rational evaluation in folk phytonym. Rational and emotional in Russian. Interuniversity collection of scientific papers. Moscow (in Russian).

11. Levus hkin, I.N. (2016). Ma rriage contract in the Russian Federation. Moscow (in Russian).

12. Semnov, Y.V. (2003). Etymological dictionary of the Russian language. Moscow (in Russian).

13. Sinyukov, V.N., Si nyukova, T.V. (2010). On the development of university a nd a pplied legal education in Russia. State a nd Law , 3, 33-42 (in Russian).

14. Turanin, V.Yu. (2009). The use of borrowed terminology in the texts of modern Russian laws: pos sibilities and limits. Modern Law, 4, 1417 (in Russian).

15. Heidegger, M. (1993a). Pa th to language (Pp. 259-272). In: Time and Being: Articles and speeches. Moscow (in Russian).

16. Heidegger, M. (1993b). Letter on Humanism (Pp. 192-220). In: Time and Being: Artides and speeches. Moscow (in Russian).

17. Rorty, R. (1967). The Linguistic Turn. Chicago: University of Chicago Press.

\section{Citation:}

Насыров Р.В. О значении лингвистического поворота в исследовании права // Юрислингвистика. - 2019. - №12. - С. 5-10.

Nasyrov, R.V. (2019). On the importance of linguisticturn in lawstudies. (2019). Towards the "crime of violence" definition in the Criminal Code of the Russian Federation. Legal Linguistics, 12,5-10.

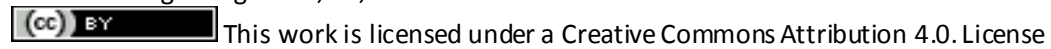

